\title{
The Safety and Efficiency of Addressing ARDS Using Stem Cell Therapies in Clinical Trials
}

\author{
Emanuele Rezoagli, Emma J. Murphy, John Laffey, \\ and Daniel O'Toole
}

\subsection{ARDS}

Acute Respiratory Distress Syndrome (ARDS) is a complex and debilitating disease of the lungs, which continues to have a high mortality rate and huge disease burden on patients. Incidence is rising, possibly due to greater awareness leading to more diagnoses rather than a change in the underlying rate. It arises from multiple etiologies, though pathogenic infection, termed pneumonia, is the most prevalent and widely studied. The distinct pathophysiology and rapid evolution of ARDS makes it uniquely challenging with regard to therapeutics development and, to date, no medicines are licensed for specific therapy. Antibiotics, ventilation, and other organ support remain intervention standards.

E. Rezoagli

Università Degli Studi di Milano-Bicocca,

Monza, Italy

Discipline of Anaesthesia, School of Medicine,

National University of Ireland Galway,

Galway, Ireland

E. J. Murphy

Athlone Institute of Technology,

Athlone, Westmeath, Ireland

J. Laffey $\cdot$ D. O’Toole $(\bowtie)$

Discipline of Anaesthesia, School of Medicine,

National University of Ireland Galway,

Galway, Ireland

e-mail: john.laffey@nuigalway.ie; daniel.otoole@ nuigalway.ie

\subsection{Definition and Diagnosis}

In 1967 Ashbaugh and colleagues [1] recognized a specific clinical pattern characterized by an acute onset of elevated respiratory rate, hypoxemia resistant to high $\mathrm{FiO}_{2}$, bilateral lung infiltrates on chest X-ray in the absence of cardiogenic edema and the presence of a heterogeneous number of risk factors that can lead to the same syndrome [2]. The first formal definition of ARDS was developed at the American-European Consensus Committee in 1994 [3].

1. Acute onset.

2. Presence of bilateral infiltrates at the chest X-ray.

3. Pulmonary wedge pressure $\leq 18 \mathrm{mmHg}$ or no clinical evidence of high left atrial pressure (to rule out a cardiogenic cause of lung edema).

4. Hypoxemia, regardless of the applied levels of positive end expiratory pressure.

The levels of hypoxemia were used to stratify the severity of lung injury as $\mathrm{ALI}\left(\mathrm{PaO}_{2} / \mathrm{FiO}_{2} \leq 300\right)$ or ARDS $\left(\mathrm{PaO}_{2} / \mathrm{FiO}_{2} \leq 200\right)$. An updated and improved version was proposed in 2012 during a task force meeting of experts in Berlin, from which the last ARDS definition takes its name [4].

1. Rapid onset of symptoms that cannot be attributed to any underlying cause.

2. Bilateral infiltration of leukocytes from surrounding tissue to the airspace, as identified by chest X-ray. 
3. Exclusion of hydrostatic causes of edema leading to respiratory failure.

4. Impaired blood oxygenation as assessed by arterial:alveolar oxygenation ratio $\left(\mathrm{PaO}_{2} /\right.$ $\mathrm{FiO}_{2}$ ), with relative levels denoting mild $(\leq 300)$, moderate $(\leq 200)$, or severe $(\leq 100)$ ARDS.

Beyond initial diagnosis criteria, scoring systems have also been devised to assess degree of injury, including APACHE [5] and Murray [6] scales for adults and PRISM [7] and PIM [8] scales for pediatric patients. It was subsequently shown that the Berlin definition criteria of ARDS are adaptable also for the pediatric population $[9,10]$.

ARDS can arise from pneumonia, sepsis, and overaggressive ventilation strategies, while other less common causes include smoke inhalation, near-drowning, and poisoning $[11,12]$. Only very recently has an accurate picture of in-hospital ARDS incidence been attained [13, 14], although prevalence as regards to the general population is still somewhat unclear.

\subsection{ARDS Management}

ARDS is an acute condition, generally arising within a week of an inciting event (e.g., pneumonia) essentially occuring and is resolved over a matter of days to weeks, and has a distinct acute hyperinflammatory phase [15-17]. The high and imminent mortality means issues such as eventual chronic fibrosis development may be secondary considerations compared to immediate restoration of lung function, specifically adequate blood oxygenation. Broad-spectrum antibiotics, given as early as possible where infection is known or suspected to be present, as is support of gas exchange, usually via assisted ventilation or in more severe cases, if available, extra-corporeal membrane oxygenation (ECMO) support [18]. The core treatment of ARDS is based on supportive measures that primarily aim at gaining time to allow the antibiotic treatment or the patient immunologic system to defeat the primary cause of ARDS. Mechanical ventilation strategy includes: the use of low tidal volume ventilation, inspiratory pressure, higher positive end expiratory pressure and using prone positioning, and administering neuromuscular blockers in higher severity ARDS [19-21]. Current guidelines supporting protective mechanical ventilation is aimed at preventing the risk of ventilator-induced lung injury [22] in patients with ARDS. The pathophysiologic reason behind this is based on the concept of the "baby lung" [23], which has reduced compliance caused by the severe decrease of lung aerated volumes, and is defined based on CT scans over the course of initial ARDS diagnosis (0-7 days) and the subsequent fibroproliferative response (15-20 days) [24, 25].

It might also be argued that despite the era of protective mechanical ventilation [26], large tidal volumes are still fundamental for mechanical ventilation daily management [13], and adjunctive measures such as proning [27] and neuromuscular blockers [28], while proven to have a positive effect on outcome, have not been fully implemented yet [13].

Furthermore, ARDS mortality remains high, despite considerable advances in terms of antibiotic stewardship and antibiotic treatment options [29-32] and fluid management [31,33] to face up the two main risk factors leading to ARDS, pneumonia, and sepsis [13].

The multimodal nature of ARDS also necessitates a multimodal approach to treatment, which cannot be met with traditional small molecule or recombinant protein medicines. A wide variety of anti-inflammatory pharmacologicals, proteins, and antibodies have demonstrated promise in the laboratory but have failed in clinical trial (reviewed in [34]). Of relevance here is the fact that injury and repair responses are intimately linked phenomena at the cell signaling and transcriptional level, and blanket inhibition of inflammation may delay or even prevent essential regenerative processes that restore lung tissue to normal function [35-37]. An idealistic treatment of ARDS should target multiple mechanisms and biologic pathways instead of aiming at a single exclusive target. This hypothesis is supported by: (1) the heterogeneity of the mechanisms involved in the lung injury, (2) decades of negative randomized clinical trials 
with pharmacologic and other therapies and (3) the new upcoming evidences about the role of biologically distinct pathways and response to treatment in specific subsets of ARDS patients as recently observed by the identification of specific endotypes and phenotypes [38-40].

In light of these considerations, cell-based therapies with mesenchymal stem/stromal cells (MSCs) have been proposed as novel therapeutics in the treatment of ARDS, due to their broad immunomodulatory effect during inflammation, their enhancement of host defense through antimicrobial mechanisms, and their lung healing potential through the activation of repairing mechanisms [41].

\subsection{Epidemiology}

ARDS occurrence remains as high as $10.4 \%$ of all ICU admissions, rising up to $23.4 \%$ of mechanically ventilated patients. ARDS still appears to be an under-recognized syndrome, with up to $40 \%$ as recently reported in the Large observational study to Understand the Global impact of Severe Acute respiratory FailurE (LUNG SAFE) study [13]. Furthermore, ARDS mortality is still estimated as high as $40 \%$.

\subsection{Pathology}

The pathophysiologic hallmark of ARDS is the well-known diffuse alveolar damage (DAD), which leads to the characteristic protein-rich nonhydrostatic pulmonary edema during ARDS [33, 42-44]. Considering that a match among clinical signs and pathology findings is far from being perfect, it is relevant that DAD is highly associated to the category of nonresolving ARDS [45] and that DAD predicts higher mortality in ARDS compared to patients with non-DAD ARDS [46]. Excess alveolar fluid blocks gas exchange at the alveolar epithelial surface, while surfactant inactivation by infiltrating albumin and other substances [47-49] damages fluid tension leading to alveolar collapse. Even for patients undergoing ventilation, eventually ventilation/perfusion (V/Q) mismatch occurs where oxygen delivered to the pulmonary space fails to reach the bloodstream and there is impairment of $\mathrm{CO}_{2}$ clearance, leading to systemic hypoxemia and hypercapnia.

At the cellular and molecular level, the initial phase of ARDS arising from pulmonary infection involves resident pulmonary macrophage defenses being overcome, and the epithelial cell layer lining the alveolus begins to produce proinflammatory cytokines [50]. These signals initiate the recruitment of circulating leukocytes, including neutrophils, macrophages, and B-cells, to migrate up a chemokine concentration gradient to the lung tissue, where these cells release matrix metalloproteinases that enzymatically digest connective tissue facilitating entry to the airspace [51]. Recruited infiltrating cells produce a wide range of noxious substances including superoxide radicals [52-58], leukotrienes [59-64], and antimicrobial peptides [65-67] and further cytokine cocktails in an attempt to destroy the infectious agents. In ARDS, a section of these substances is uncontrolled and induce damage to the lung tissue itself leading to fluid buildup and surfactant loss. Finally as the alveoli fill with liquid and the integrity of the epithelial and endothelial barrier is compromised, gas exchange deteriorates and hypoxemia and hypercapnia result. In later phases of ARDS during systemic inflammatory response syndrome (SIRS), patients may suffer from functional immune-suppression and have heightened susceptibility to additional infection [68-70]. While ARDS presents an acute onset after the exposure to the causing factor, its evolving process starts with acute exudation and infiltrates of acute inflammatory cells into the alveoli within 1 week. During the second week a subacute deposition of collagen fibers are produced by fibroblasts. The syndrome typically resolves through a chronic stage characterized by alveolar macrophage infiltration into the alveoli and a fibrotic repairing process of the lung parenchyma [11].

\subsection{MSCs for ARDS: A Promising Potential Therapy}

MSCs have generated interest for a wide range of regenerative medicine applications and appear to 
have broad immunomodulatory properties rendering them attractive for autoimmune and other inflammatory disorders. Initial safety has been amply demonstrated [71, 72], although some questions remain over hypersensitivity to repeat dosing in non-ARDS models which will only be answered over time [73, 74]. As further conditions are likely to have MSCs licenses as a medicinal therapeutic, this will be of added relevance where MSC therapy may be employed in the same patient for sequential separate disease instances.

MSCs accumulate in the lungs initially after IV administration [75-77] and can remain viable there for up to $24 \mathrm{~h}$ [78] after which this time MSCs disappear, suggesting any therapeutic effect has already been conferred to the host; however, it is not clear what happens to MSCSs after they have left the lungs. Interestingly, recent stem cell therapy research in other diseases has indicated the lung is crucial to licensing of MSC to ultimately allow their beneficial effects [7981], suggesting an immunomodulatory effect that outlasts the MSC's presence in the body.

The MSC's responsiveness to the injury milieu [82-85] and diverse range of effects on multiple pathological and repair processes has made them, theoretically, an ideal candidate for ARDS interventional studies [86] (Fig. 12.1). Indeed, many of the leukocyte subpopulations involved in ARDS pathology have been shown to have direct interaction with MSCs [87-89], while direct antibacterial activity [65] is to be considered an added bonus. Also, the fact that most patients with ARDS require tracheal intubation to permit support of lung function opens up the possibility of direct delivery to the lung airspace of MSC or MSC derivatives [90], although since patients are also almost certain to have IV access obtained and there have been, to date, no demonstrated efficacy advantages observed in delivery of MSC intratracheally over IV [91] in ARDS models, this remains a point of urgent future investigation.

Inviting as MSC therapy may appear, the timecourse and whole body nature of ARDS demand a specific set of considerations around preparation, storage, and administration to be resolved before deployment of MSCs to the clinic. Translation of experimental findings from animal models to the patient are also problematic, with uncertainty regarding dose scaling and testing of the human MSCs destined for patients in nonhuman models, where DNA/RNA sequence and protein/ligand binding incompatibilities warrant extra attention.

\subsection{Ex Vivo Human Lung Models}

In a first report in 2009, Lee et al. explored the potential role of allogenic human MSCs in the treatment of ARDS induced by E. coli endotoxin in an ex vivo perfused human lung [92]. The authors administered allogeneic human MSCs or MSCs-derived conditioned medium at $1 \mathrm{~h}$ after the injury induction. Fluid balance was normalized by the decrease of the extravascular lung water, restoring the alveolar fluid clearance (AFC) and by improvement of lung endothelial barrier permeability. The alveolar epithelial fluid transport was in part coordinated by the keratinocyte growth factor (KGF), secreted by the MSCs, which restored the correct function of the amiloride-dependent sodium transport.

Some years later, it was observed that clinicalgrade MSCs, administered via the lung perfusate or directly into the right middle lobe, could decrease neutrophil influx and inflammation, effectively cleared bacteria, confirming the contributing role of the KGF, and restored the clearance of the alveolar fluid, with a relevant improvement of the lung histology [93]. In 2014, it was observed in a follow-on study that intravenous administration of clinical-grade allogenic human MSCs could increase the AFC at $4 \mathrm{~h}$. The role of $\mathrm{KGF}$ in the AFC was confirmed by the study of a neutralizing antibody of KGF that could decrease the AFC activity [94]. Recently, the same group explored the effects of microvesicles (MVs) released by human mesenchymal stem cells in their established ex vivo human lung perfusion model of bacterial pneumonia. The investigators reported positive results highlighting the beneficial effects of MSC MVs in increasing lung antibody forming cells, in decreasing the lung permeability, and improving the bacterial clearance, particularly when MSCs were pre- 


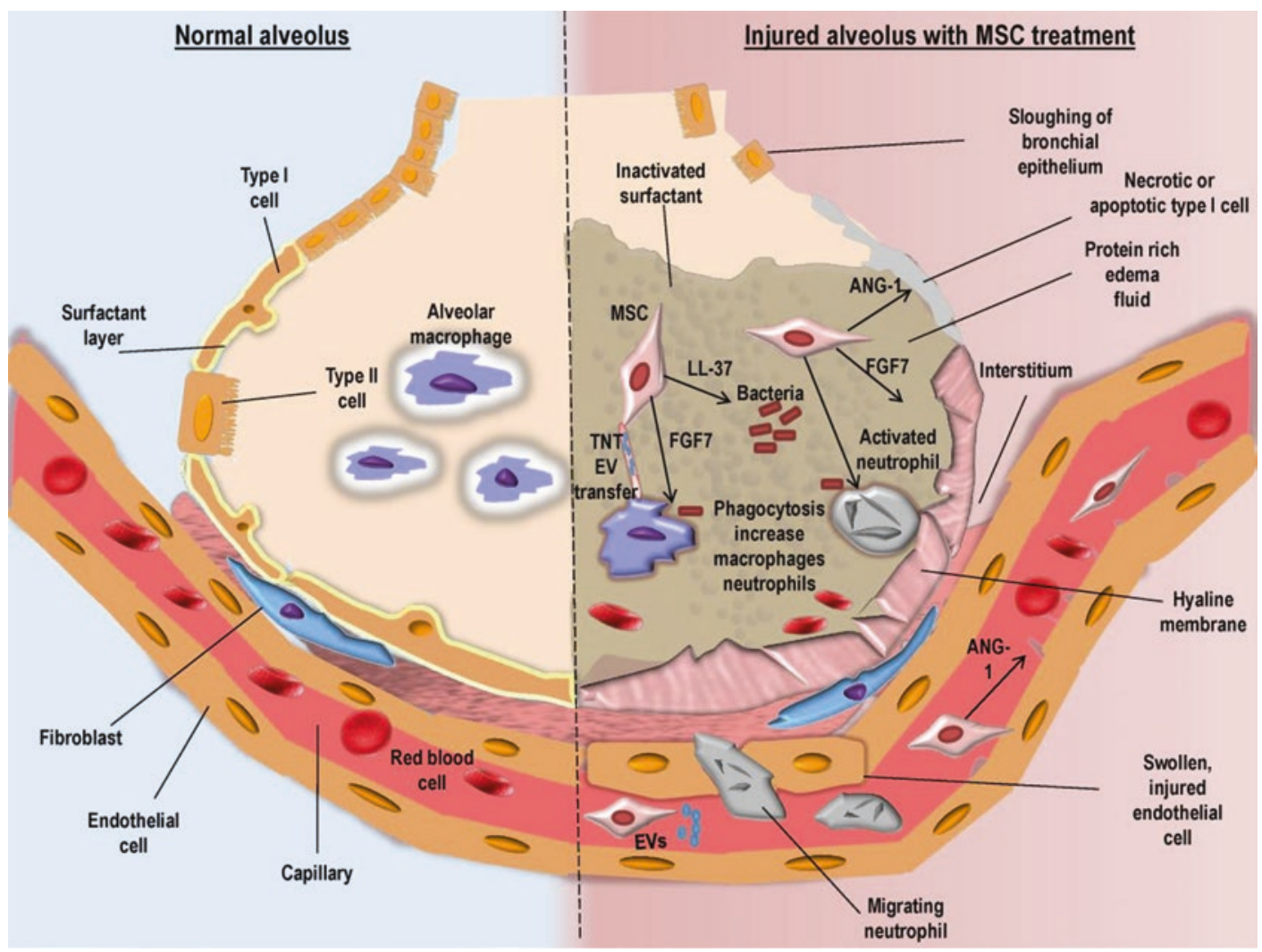

Fig. 12.1 Possible mechanisms of action of the MSC in the ARDS alveolus and surrounding vasculature. Left side: healthy alveolus. Right side: during injury, proteinrich edema fluid and inflammatory cells permeate the alveolus. MSCs have been demonstrated to alleviate the pathophysiological symptoms of ARDS through the secretion of paracrine factors, cell-to-cell contact and mitochondrial transfer (TNT and EV release). Indirect and direct contact of MSCs has been shown to reduce the permeability of alveolar epithelium and increase fluid clearance. Through the secretion of ANG-1, endothelial and epithelial repair is increased. Reduction of neutrophil migration also improves endothelial and epithelial barri- ers. Release of KGF promotes an increase in alveolar fluid clearance. Bacteria clearance is achieved through the direct release of the antimicrobial peptide LL-37 or through increased phagocytosis by neutrophils and macrophages mediated by the release of cytokines including FGF-7 or by transfer of micro vesicles through TNTs. Mitochondrial transfer to epithelial cells also increases surfactant release. A few mechanisms of action of MSCS in ARDS have been displayed in this diagram. EVs extracellular vesicles, TNT Tunnelling Nanotubules, ANG-1 angiopoietin-1, $P G E 2$ prostaglandin E2, $K G F$ keratinocyte growth factor, $L L$-37 peptide $\beta$-cathelicidin treated before isolation of MVs with a Toll-like receptor 3 agonist, polyinosinic:polycytidylic acid (Poly(I:C)) [95].

\subsection{Mechanistic Considerations for Clinical Therapy}

Allogenic MSCs have the ability to avoid detection of the immune system and it is assumed that this evasion is due to the low expression of the major histocompatibility complexes (MHC) I and II, while MSCs also do not express CD80 and CD86 which are identified T-cell stimulators [96]. Therefore autologous MSC administration is considered a viable therapeutic option as the likelihood of an immune response is extremely low.

The routes of administration will influence the MSCs ability to differentiate, their immunogenic 
effect, and ultimately their survival [97]. Some studies have contradicted the MSC's proposed ability to evade immunological detection. MHC II protein expression analysis on MSCs has been shown to be higher than originally documented [98-100]. In vivo studies have also shown that allogenic MSCs are not immune privileged and have the potential to cause an immune response, while other research has contradicted findings and stated MSCs are immune privileged [101-104].

MSC efficacy has been demonstrated in multiple preclinical models of ARDS [90, 93, 94, 105-111], while MSC products including conditioned medium and extracellular vesicles have also shown promise [91, 94, 107, 112-117]. These are interesting in that they avoid safety and cryostorage issues associated with whole cell delivery and may be more compatible with direct delivery to the airspace by nebulizer. MSCs have been shown to reduce inflammation and improve bacterial clearance [107] through direct antimicrobial peptide release such as LL-37 and indirectly through the modulation of phagocytic activity in BAL monocytes [108] as well as alveolar resident monocytes specifically [93].

More recently, MSCs have been documented to protect from injury via direct interaction through tunneling nanotubules (TNT) or formation of connexin 43 gap junctions [118-125]. It has been demonstrated that mitochondrial transfer from MSCs to alveolar epithelial cells improved survival after endotoxin injury [118], while in a rat model of COPD, iPS-derived MSC mitochondrial transfer to bronchial epithelial cells was also observed [126]. MSCs have been shown to transfer mitochondria to macrophages in vitro and in vivo, improving macrophage function and enhancing phagocytosis [127]. In a mouse model of $E$. coli-induced pneumonia it was reported that therapeutic effect was dependent on transfer of MSC mitochondria to alveolar macrophages through TNT, enhancing antimicrobial activity and phagocytosis [128]. While it is unclear whether the mechanism of action in vivo is due to an enhancement of a normal mitochondrial function or restoration of dysfunctional mitochondria, there is some evidence for damaged mitochondrion, e.g., downregulated
NDUFB8 (complex I) and ATP synthase (complex V), in ARDS meaning the latter is a distinct possibility [129, 130].

\subsection{Production Considerations for Clinical Cell Therapies}

For ARDS, autologous stem cell therapy is not an option as there is insufficient time to isolate and expand patient MSCs while the rapid onset nature of ARDS demands a cryopreserved MSC product. Cryoprotective agents are used to protect the cellular components from crystal formation and osmotic shock and membrane damage during the slow freezing process, preserving the fine structures of cells [131]. For clinical applications, MSCs are typically frozen to at least $-150{ }^{\circ} \mathrm{C}$ at a controlled rate of $1-5{ }^{\circ} \mathrm{C}$ per minute in $5 \%$ or $10 \%$ dimethyl sulfoxide in an electrolyte solution and added protein, typically human serum albumin [132]. Despite extensive optimization, the process can cause damage and affect cell viability [133-135] and inadequate insight into how MSCs function after systemic infusion remains an issue [134, 136-139].

Freeze-thawed MSCs, in comparison to cells harvested from continuous cultures, have diminished immunomodulatory properties as well as a reduced responsiveness to proinflammatory cytokines [140]. The immunomodulatory effects of MSCs is affected by cryopreservation, launching a heat shock protein response [141]. In vivo experiments have shown that cryopreserved are less well tolerated. In a clinical application where predominant indications included graft versus host disease (GvHD) and tissue injury in hemorrhagic cystitis, therapeutic properties of freezethawed and freshly harvested MSCs were compared. A $100 \%$ response rate was observed in patients treated with fresh cells at a low passage compared to patients treated with cryopreserved freeze-thawed cells at a higher passage, with cryopreserved MSCs eliminated faster by compliment after exposure to recipient blood [140]. The thawing process can damage cell surface proteins and this abnormality attracts the binding of complement initiating clearance by phagocy- 
tosis [142-144]. After complement exposure, there is an $80 \%$ decrease in cell viability in cryopreserved cells compared to a $50 \%$ decrease in fresh MSCs [141, 145]. However activation of complement may not be negative as recognition of opsonized MSCs are hypothesized to induce an M2 phenotype, producing anti-inflammatory mediators [140]. Macrophages can display various phenotypes, with the two being described as M1 and M2. M1 phenotypes are generated by the classical pathway [146, 147] and produce abundant inflammatory cytokines such as tumor necrosis factor (TNF)- $\alpha$ and interleukin (IL)-12, and reactive oxygen species. M2 phenotypes are generally activated by the alternative pathway and express a variety of lectins, protein, and scavenger receptors [146-148].

While various research have demonstrated that umbilical cord (UC) [149-152] and adipose tissue (AT)-derived [153] MSCs have a faster population doubling time than bone marrow (BM) sourced, attaining human-sized doses of the order of $10^{9}$ cells is still a daunting task. Additionally, there is currently no data published on whether there is an upper limit on MSC population doubling that still retains therapeutic efficacy. Kern et al. compared the senescence ratio of AT-MSC to BM-MSC and found that BM-MSC had a growth threshold of passage 7 , whereas AT-MSC had a threshold of 8 [154], but efficacy itself may be lost long before senescence arises. In addition, MSCs isolated from patients with advanced age [155, 156], diabetes [157], rheumatoid arthritis [158], or indeed ARDS itself [159] have decreased activity, including lower regenerative and differential potential and therefore autologous MSC therapy in patients with significant chronic comorbidities may not be a promising approach in any case. Downregulation of inflammatory marker receptors may render MSCs isolated from such patients less responsive to the injury microenvironment and hence of lower overall therapeutic value [146, 147, 159].

Beyond the conventional MSC therapeutics, human embryonic stem cells (ESC) and induced pluripotent stem cells (iPSC) as new cell types have also been investigated in immunoregulation and have shown encouraging results [160-163].
iPSCs are immunomodulatory in a mouse model of allergic inflammation [164], while their systemic administration inhibited serum levels of IgE and TH 2 cytokines (IL-4, IL-5 or IL-13) with better survival and engraftment rate after transplantation compared to adult tissue derived MSCs [163, 165]. There are also, variations in age related to DNA methylation levels, which is correlated to differential abilities, with ESCderived iPSC having a higher proliferation and regenerative capacity [166, 167]. However, caution is still required as genetic abnormalities remain an area of concern in iPSCs [168]. Clinical studies using iPSCs found some cells in the study contained genetic abnormalities, and were consequently not used. Cells taken from elderly patients to be reprogrammed for administration can come with increased risks of genetic abnormalities [168], demonstrating the need for screening of cells before infusion if autologous cells are ever to be used in elderly patients.

\subsection{Clinical Trials- Demonstrating Safety in ARDS}

Clinical trials utilizing MSCs for ARDS patients are in phase 1-2 studies and focused on safety, tolerability and feasibility concerns. We are far from being able to claim MSC therapy is a viable option for ARDS. However, during the last decade, promising preclinical evidence supports the hypothesis of a potential benefit in treating ARDS patients with MSCs [169]. Despite the many studies into the potential clinical benefit of MSCs in ARDS that have been proposed over the last years and posted on clinicaltrials.gov, most of them are still currently ongoing or they lack a status update. Furthermore, few studies have disclosed the initial safety results (Table 12.1). The first clinical trial where MSCs were used to treat ARDS was reported in 2014 (NCT01902082), where Zheng and coworkers administered $1 \times 10^{6}$ AT-MSCs $/ \mathrm{kg}$ of body weight or saline in a $1: 1$ fashion in 12 patients with moderate and severe ARDS. The investigators reported that the administration of allogeneic MSCs was feasible and 


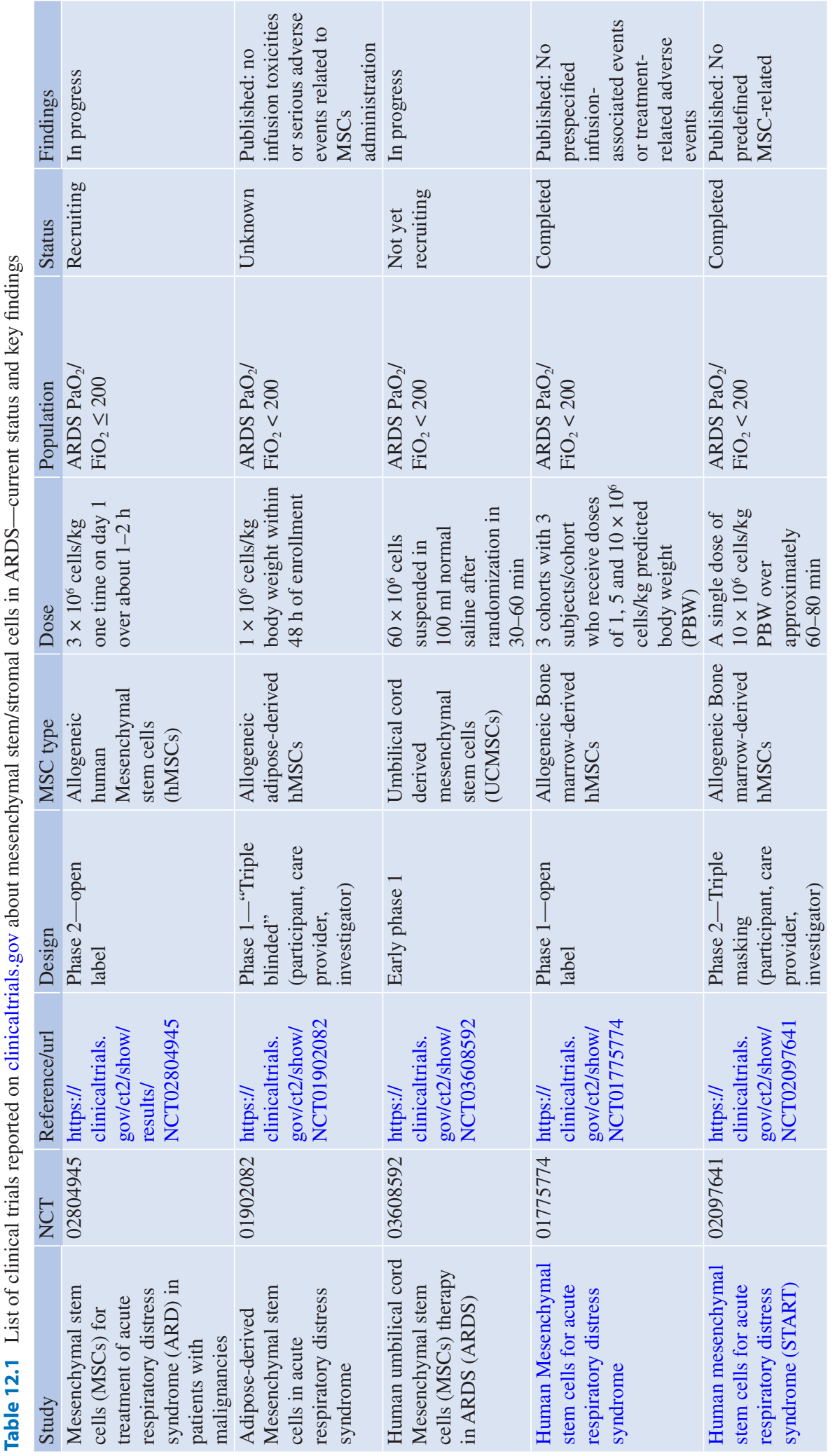




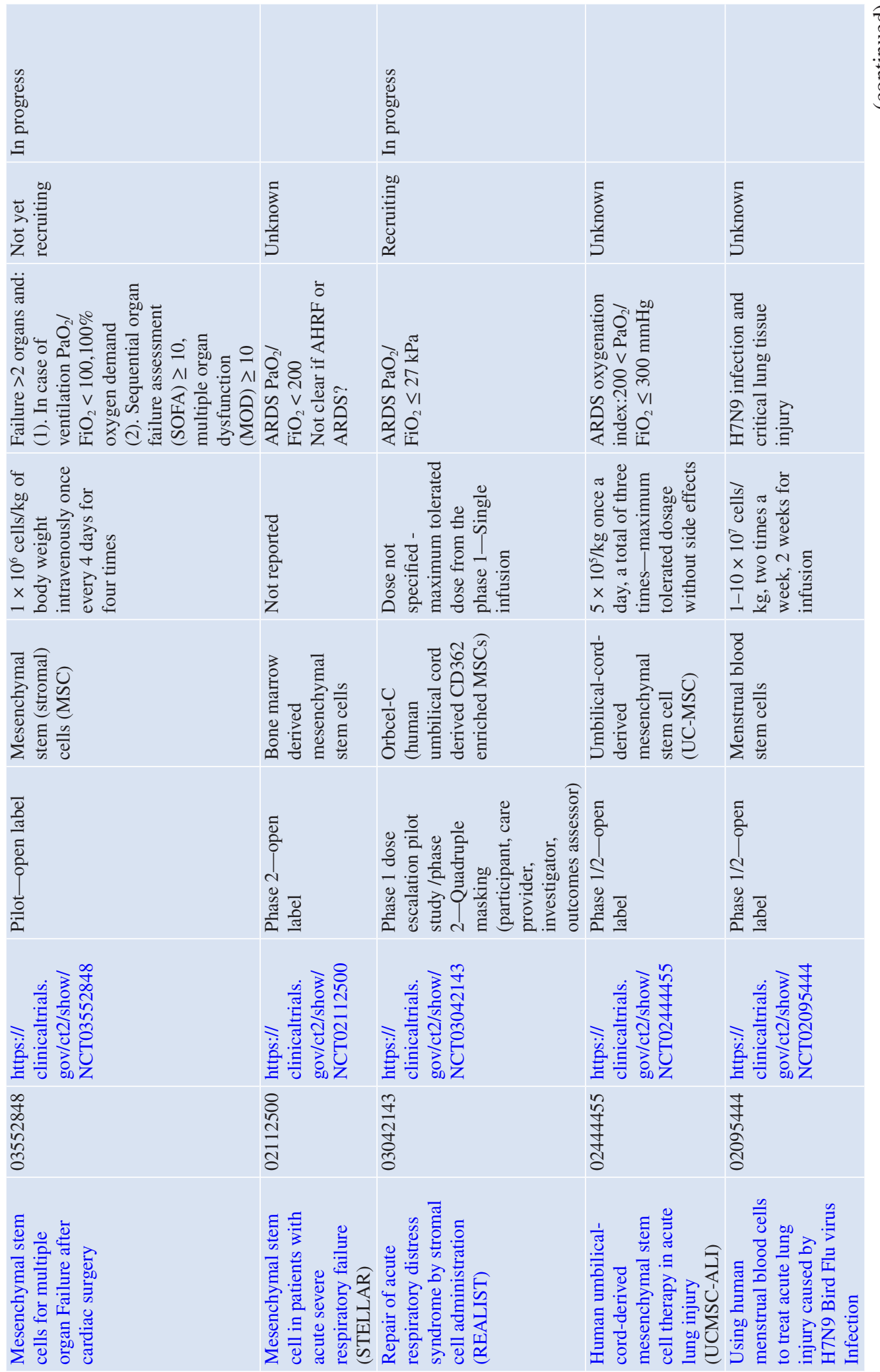




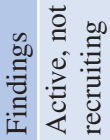
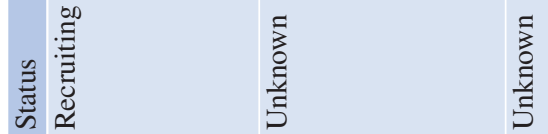

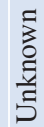
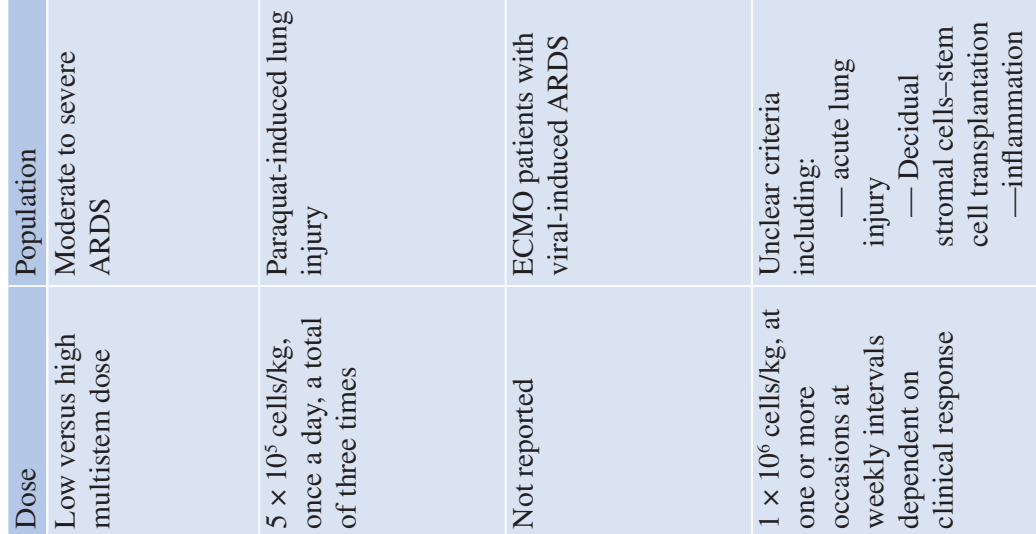

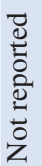

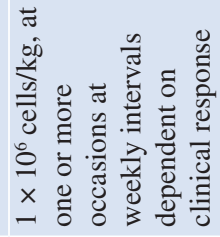

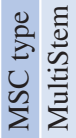

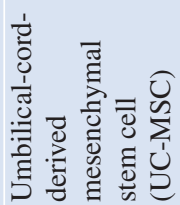

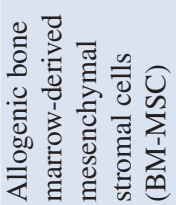

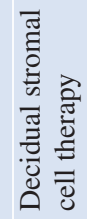

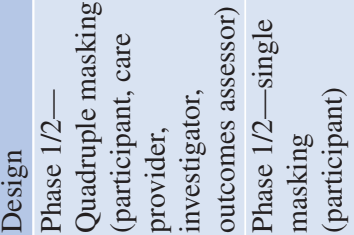
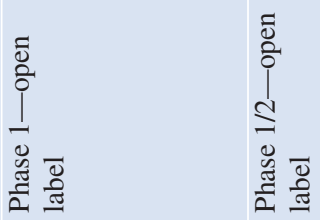

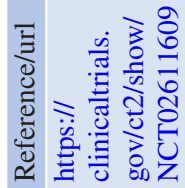
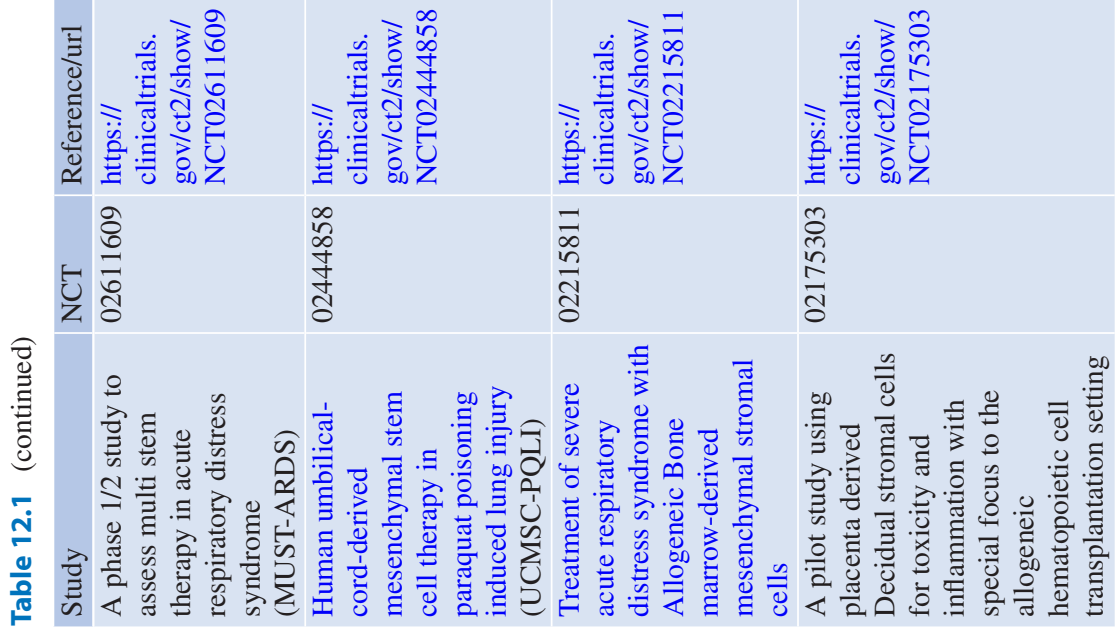
safe with no infusion toxicities or serious adverse events related to MSCs in the treatment group and with no differences in terms of adverse events and biomarkers of lung injury between the MSCs and the placebo group [170].

In 2015, Wilson J.G. and coworkers tested the safety of BM-MSCs in a multicenter phase $1 \mathrm{~b}$ dose-escalation study in patients with moderatesevere ARDS, with $\mathrm{PaO}_{2} / \mathrm{FiO}_{2}$ less than $200 \mathrm{~mm}$ $\mathrm{Hg}$, a positive end-expiratory pressure (PEEP) $\geq 8 \mathrm{cmH}_{2} \mathrm{O}$, and bilateral infiltrates at the frontal chest X-ray (NCT01775774). Nine patients were enrolled and three groups of three received three doses of MSCs intravenously (1, 5, or $10 \times 10^{6} \mathrm{MSC} / \mathrm{kg}$ ideal body weight). The investigators reported no significant difference in biomarkers of inflammation (IL-6, IL-8), lung epithelial (receptor for advanced glycation end products-RAGE) and endothelial injury (Ang-PT2) among the groups. MSC administration was safe and the authors reported neither infusion-associated events nor serious adverse events. The viability of the MSCs infused ranged from $50-63 \%$ [171].

The same investigators recently reported the findings of a double-blind multicenter randomized phase 2a clinical trial testing the safety of BM-MSCs versus placebo in ventilated patients with moderate-severe ARDS, with $\mathrm{PaO}_{2} /$ $\mathrm{FiO}_{2}<27 \mathrm{kPa}$ and PEEP $\geq 8 \mathrm{cmH}_{2} \mathrm{O}$. Patients randomly received in a $2: 1$ fashion $1 \times 10^{6}$ BM-MSCs/kg ideal body weight or placebo. The primary objective of this investigation was the safety of MSCs in an intention to treat analysis (NCT02097641). No patient in the MSCs treatment group experienced any adverse respiratory or hemodynamic events. The treatment group had higher APACHE III score, minute ventilation, and PEEP compared to placebo. No statistically significant 28-day mortality difference was observed among treatment and placebo group, even after adjustment with the APACHE III score, while a trend in a lower number of ICUfree days to day 28 was reported in the treatment group compared to placebo. Of importance, there was higher absolute 28 day and 60 day mortality in the MSC group, although it is unclear at this point if there is any clinical significance to this result or if it was related to variability in MSC viability on administration or some other quality issue.

Furthermore, a higher severity of illness at baseline - quantified by the SOFA and APACHE III scores-was present in the MSC group compared to the placebo group and mortality in the MSC group and in the placebo group was lower and higher than anticipated, respectively.

However, this RCT was not powered for efficacy, as per the Food and Drug Administration mandate to clearly demonstrate safety before targeting lung oxygenation or compliance as in a phase $2 b$ trial. The viability of the MSCs infused ranged from $36-85 \%$ [71].

The range in MSC viability was unanticipated and only discovered after study completion. The authors reported a significantly higher MSCs viability after centrifugation when MSCs were thawed compared to when the cells were washed to remove dimethyl sulfoxide during preparation. Based on these findings the investigators conducted a posthoc analysis and observed that plasma angiopoietin-2 levels in the intermediate and highest tertiles of MSCs viability were significantly lower in the MSCs treatment group at $6 \mathrm{~h}$ after administration compared to placebo, and albeit nonsignificantly, the oxygenation improved at day 2.

These results suggest that the administration of MSCs with a high viability is required to target an improvement in efficacy. Recent experimental data on the comparison of different cell products reports that fresh BM-MSCs are 14\% more viable compared to cryopreserved ones [172]. Furthermore, delivery of MSC immediately upon thawing instead of thawing and washing the MSCs could enhance MSC viability, as observed by Matthay MA et al [71]. This is an unusual finding, as washing of MSC in physiological buffer has not been considered traditionally to have any impact on viability, and warrants further investigation.

Simonson and colleagues reported data on the clinical outcomes of two patients with severe ARDS who received allogenic BM-MSCs. MSC administration was safe and no adverse events were reported during infusion. The investigators reported a decrease of plasma and BAL proinflammatory cytokines, chemokines, miRNAs, 
and biomarkers of epithelial apoptosis and alveolar-capillary fluid leakage. One patient developed pneumonia 5 days after cell administration, which resolved after antibiotic therapy and the patient was subsequently extubated 4 weeks after MSCs administration. The second patient was extubated 12 days later [92].

Very recently, Athersys disclosed in a press release the positive results for the MUST-ARDS study about MultiStem ${ }^{\circledR}$ Cell Therapy in patients with moderate-severe ARDS (NCT02611609). After an initial dose confirmation phase $(n=6)$, Athersys confirmed the tolerability and the safety profile of the MultiStem ${ }^{\circledR}$ treatment $(n=20)$ with no adverse events during administration, and lower levels of inflammatory biomarkers compared to the control group $(n=10)$. Furthermore, despite the study was not powered for efficacy outcomes, MultiStem ${ }^{\circledR}$ cell therapy was associated with better short term prognosis, as shown by a lower mortality rate ( $25 \%$ versus $40 \%$ ), higher ventilator-free (12.9 versus 9.2) and ICUfree days (10.3 versus 8.1) compared to control. Further findings will be unveiled at end of the collection of the 1-year follow-up data, as aimed according to the study design. (http://www.athersys.com/news-releases/news-release-details/ athersys-announces-positive-results-its-exploratory-clinical).

All the studies currently ongoing in the field of MSCs and ARDS are safety studies (Phase 1, $2,1 / 2$ ) (Table 12.1). At the moment there are still additional issues that need to be overcome: (1) improvement of MSCs bioavailability by the optimization of the cell preparation and storage [71]; (2) the modulation of the microenvironment [173]; (3) the characterization of the specific phenotypes/endotypes of ARDS potentially more suitable to respond to cell therapy $[39,40]$. This might enhance the likelihood of success in subsequent efficacy (Phase 3) studies.

\subsection{Future Directions}

\subsubsection{Patient Stratification}

ARDS is classified by the Berlin definition into different severity categories, according to the degree of hypoxemia, and each associated with increasing mortality rates. However, other evidence suggests that: (1) either the etiology (i.e. pulmonary versus extrapulmonary ARDS) [174177], or (2) the macroscopic ARDS presentation at radiological imaging [178] or (3) the levels of different inflammatory biomarkers contributing to different biological patterns of ARDS might play a key role in stratifying the outcome of this syndrome [179]. Pulmonary ARDS was associated with longer total ventilation time and longer ICU stay compared to extrapulmonary ARDS [180]. ARDS patients with a higher epithelial injury, as observed by higher levels of soluble form of the receptor for advanced glycation end product (sRAGE), showed a specific nonfocal CT lung pattern, which was associated with higher mortality compared to the focal pattern [178].

The ARDS Network proposed a novel classification of ARDS with two distinct subphenotypes, which included different clinical and laboratory characteristics [39]. Interestingly, in a secondary analysis of the ARMA [26, 181, 182] and the ALVEOLI trials [183], the investigators could identify a specific pattern of ARDS that the investigators named hyperinflammatory subphenotype, phenotype 2 . Phenotype 2 showed higher plasma concentrations of inflammatory biomarkers greater prevalence of vasopressor use and lower serum bicarbonate concentrations than phenotype 1 . The hyperinflammatory subphenotype could differentiate a subgroup of patients with a higher mortality rate.

In light of the heterogeneity of ARDS, attempts have been made to optimize treatment regimens [173], and stratification parameters are emerging among recipients of MSC therapy which may be of relevance to ARDS patients [184].

\subsubsection{Large-Scale Cell Manufacture}

As detailed earlier, generation of human-sized doses of GMP quality MSCs, for the numbers of patients needed for large-scale clinical trials (and subsequent clinical therapy), is not a trivial undertaking. Preclinical studies typically use between $1 \times 10^{6}$ and $10 \times 10^{6} \mathrm{MSCs}$ per $\mathrm{kg}$ of 
bodyweight or ideal bodyweight of the patient, and clinical trials have been designed with these doses in mind. In light of the observed relatively low cell viability in ongoing trials, production of the order of $10^{9} \mathrm{MSC}$ may be required to reach the upper doses when allowance for dead cells is calculated. Coupled with the lack of information with regard to passage or population doubling at which efficacy is lost, this will likely necessitate pooled donor batches to enter the MSC isolation and production process. Considerable work is being concentrated on this area both academically and industrially to optimize and automate, including the utilization of xeno-free media that allays fears of contamination with viruses or other as yet unknown contaminating factors.

The preponderance of preclinical work with MSCs has involved freshly harvested MSCs and this will remain an impractical and unlikely therapeutic for the clinic. Despite the development of rapid shipping solutions from manufacturing facility to clinical site, and research into supportive media to extend the MSCs' effective lifespan in suspension prior to administration, it is probable that a cryopreserved MSC will become the choice in the long term. Cryopreservation at the clinical site or expedited transport from manufacturing facilities will be required, but it remains to be determined what further equipment such as centrifuges and viability assessment assays will be needed to prepare the MSC dose and allow quality control prior to administration to the patient.

\subsubsection{Lack of Clearly Defined Mechanism of Action}

Despite a myriad of possible effector mechanisms by which the MSC may alleviate ARDS severity, including secreted antimicrobials, cytokines, extracellular vesicles, and other factors, and the observed influence MSCs have on leukocytes, it has remained difficult to ascertain which of these mechanisms are of importance to the MSCs' efficacy. Indeed several studies that have sought to replicate the various mechanisms proposed through administration of MSC-produced factors have failed or not reproduced the efficacy of the MSC itself, indicating critical gaps in our knowledge of MSC action in ARDS and suggesting interpretation of unsuccessful or even successful follow on clinical trial will be difficult. If the mechanism remains unknown, then interactions with other drugs or comorbidities will always be unpredictable.

\subsubsection{Lack of MSC Potency Assay}

Related to both production and mechanism, a critical limiting factor in successful deployment of MSC therapy to the clinic is the lack of defined assays to accurately predict MSC potency in the ARDS patient. Many cell manufacturers and research groups have proposed small, easily quantified molecules such as aldehyde dehydrogenase (ALDH) [185] or indoleamine 2,3-dioxygenase (IDO) [186], which correlated well with in vitro tests such as T-cell expansion inhibition or in vivo tests in ARDS animal models. However, as the MSC's mechanism of action in ARDS remain unclear, these factors can only be considered correlative and not conclusive proof of likely efficacy in the human patient.

\subsubsection{Beyond the MSC?}

Determining the mechanism(s) of action of the MSC specifically, however, will lead to us a question: do we need the cell at all? A suite of effectors produced by MSC cultures, or indeed by similar cell types engineered to replicate or improve upon the MSC secretome while being more open to manipulation and expansion, could replace cell therapy entirely. Also, as alluded to already, these factors will be likely easier to analyze, store, and deliver than the MSC they are derived from. Presuming cell-contact dependent mechanisms such as TNTs are the sole means underlying the MSC's efficacy in ARDS, we may ultimately see an MSC product cocktail available in stable, offthe-shelf format that can be delivered IV or intratracheally by nebulizer that will reproduce the efficacy initially demonstrated with the IV-delivered cryopreserved whole cell. 


\subsection{Conclusions}

ARDS has been a stubbornly challenging syndrome to address clinically for decades. Despite gradual improvement in supportive care for the patient, specific therapies have proven elusive. The MSC is an exciting prospect, as it is a real paradigm shift from traditional approaches, due to its ability to respond to the level and nature of injury, having both direct and immunomodulatory properties, and a multimodal mechanism of action that targets multiple pathologies seen in the ARDS patient. Issues around dosing, MSC production, and potency reproducibility remain but are being addressed. We look forward to the conclusion of the many current and planned clinical trials to determine the true therapeutic potential of MSCs for those suffering from this devastating disease.

\section{References}

1. Ashbaugh DG, et al. Acute respiratory distress in adults. Lancet. 1967;2(7511):319-23.

2. Laffey JG, et al. Potentially modifiable factors contributing to outcome from acute respiratory distress syndrome: the LUNG SAFE study. Intensive Care Med. 2016;42(12):1865-76.

3. Bernard GR, et al. The American-European Consensus Conference on ARDS. Definitions, mechanisms, relevant outcomes, and clinical trial coordination. Am J Respir Crit Care Med. 1994;149(3 Pt 1):818-24.

4. Ranieri VM, et al. Acute respiratory distress syndrome: the Berlin definition. JAMA. 2012;307(23):2526-33.

5. American College of Chest Physicians/Society of Critical Care Medicine Consensus Conference: definitions for sepsis and organ failure and guidelines for the use of innovative therapies in sepsis. Crit Care Med. 1992;20(6):864-74.

6. Murray JF, et al. An expanded definition of the adult respiratory distress syndrome. Am Rev Respir Dis. 1988;138(3):720-3.

7. Pollack MM, Patel KM, Ruttimann UE. PRISM III: an updated Pediatric risk of mortality score. Crit Care Med. 1996;24(5):743-52.

8. Shann F, et al. Paediatric index of mortality (PIM): a mortality prediction model for children in intensive care. Intensive Care Med. 1997;23(2):201-7.

9. Barreira ER, et al. Epidemiology and outcomes of acute respiratory distress syndrome in children according to the Berlin definition: a multicenter prospective study. Crit Care Med. 2015;43(5):947-53.
10. De Luca D, et al. The use of the Berlin definition for acute respiratory distress syndrome during infancy and early childhood: multicenter evaluation and expert consensus. Intensive Care Med. 2013;39(12):2083-91.

11. Rezoagli E, Fumagalli R, Bellani G. Definition and epidemiology of acute respiratory distress syndrome. Ann Transl Med. 2017;5(14):282.

12. Rezoagli E, et al. ABO blood types and major outcomes in patients with acute hypoxaemic respiratory failure: a multicenter retrospective cohort study. PLoS One. 2018;13(10):e0206403.

13. Bellani G, et al. Epidemiology, patterns of care, and mortality for patients with acute respiratory distress syndrome in intensive care units in 50 countries. JAMA. 2016;315(8):788-800.

14. Bellani G, et al. The LUNG SAFE study: a presentation of the prevalence of ARDS according to the Berlin Definition! Crit Care. 2016;20:268.

15. Ingbar DH. Mechanisms of repair and remodeling following acute lung injury. Clin Chest Med. 2000;21(3):589-616.

16. Tomashefski JF Jr. Pulmonary pathology of acute respiratory distress syndrome. Clin Chest Med. 2000;21(3):435-66.

17. Meyrick B. Pathology of the adult respiratory distress syndrome. Crit Care Clin. 1986;2(3):405-28.

18. Lee KY. Pneumonia, acute respiratory distress syndrome, and early immune-modulator therapy. Int $\mathbf{J}$ Mol Sci. 2017;18(2):E388.

19. Fan E, et al. An official American Thoracic Society/ European Society of Intensive Care Medicine/Society of Critical Care Medicine clinical practice guideline: mechanical ventilation in adult patients with acute respiratory distress syndrome. Am J Respir Crit Care Med. 2017;195(9):1253-63.

20. Ferguson ND, et al. The Berlin definition of ARDS: an expanded rationale, justification, and supplementary material. Intensive Care Med. 2012;38(10):1573-82.

21. Fan E, Brodie D, Slutsky AS. Acute respiratory distress syndrome: advances in diagnosis and treatment. JAMA. 2018;319(7):698-710.

22. Slutsky AS, Ranieri VM. Ventilator-induced lung injury. N Engl J Med. 2013;369(22):2126-36.

23. Gattinoni L, Pesenti A. The concept of "baby lung". Intensive Care Med. 2005;31(6):776-84.

24. Bhattacharyya N, Abemayor E. Patterns of hospital utilization for head and neck cancer care: changing demographics. JAMA Otolaryngol Head Neck Surg. 2015;141(4):307-12; quiz 400

25. Gattinoni L, et al. Pressure-volume curve of total respiratory system in acute respiratory failure. Computed tomographic scan study. Am Rev Respir Dis. 1987;136(3):730-6.

26. Brower RG, et al. Ventilation with lower tidal volumes as compared with traditional tidal volumes for acute lung injury and the acute respiratory distress syndrome. N Engl J Med. 2000;342(18):1301-8. 
27. Guerin $\mathrm{C}$, et al. Prone positioning in severe acute respiratory distress syndrome. $\mathrm{N}$ Engl $\mathrm{J}$ Med. 2013;368(23):2159-68.

28. Papazian L, et al. Neuromuscular blockers in early acute respiratory distress syndrome. N Engl J Med. 2010;363(12):1107-16.

29. Kalil AC, et al. Executive summary: Management of Adults with Hospital-acquired and Ventilatorassociated Pneumonia: 2016 Clinical Practice Guidelines by the Infectious Diseases Society of America and the American Thoracic Society. Clin Infect Dis. 2016;63(5):575-82.

30. Torres A, et al. International ERS/ESICM/ESCMID/ ALAT guidelines for the management of hospital-acquired pneumonia and ventilator-associated pneumonia: guidelines for the management of hospital-acquired pneumonia (HAP)/ventilator-associated pneumonia (VAP) of the European Respiratory Society (ERS), European Society of Intensive Care Medicine (ESICM), European Society of Clinical Microbiology and Infectious Diseases (ESCMID) and Asociacion Latinoamericana del Torax (ALAT). Eur Respir J. 2017;50(3):1700582.

31. Singer M, et al. The third international consensus definitions for sepsis and septic shock (Sepsis-3). JAMA. 2016;315(8):801-10.

32. Klompas M, Calandra T, Singer M. Antibiotics for sepsis-finding the equilibrium. JAMA. 2018;320(14):1433-4.

33. Matthay MA, Ware LB, Zimmerman GA. The acute respiratory distress syndrome. J Clin Invest. 2012;122(8):2731-40.

34. Rubenfeld GD. Confronting the frustrations of negative clinical trials in acute respiratory distress syndrome. Ann Am Thorac Soc. 2015;12(Suppl 1):S58-63.

35 . Weigelt JA, et al. Early steroid therapy for respiratory failure. Arch Surg. 1985;120(5):536-40.

36. Devaney J, et al. Inhibition of pulmonary nuclear factor kappa-B decreases the severity of acute Escherichia coli pneumonia but worsens prolonged pneumonia. Crit Care. 2013;17(2):R82.

37. Ward C, et al. NF-kappaB inhibitors impair lung epithelial tight junctions in the absence of inflammation. Tissue Barriers. 2015;3(1-2):e982424.

38. Famous KR, et al. Acute respiratory distress syndrome subphenotypes respond differently to randomized fluid management strategy. Am J Respir Crit Care Med. 2017;195(3):331-8.

39. Calfee CS, et al. Subphenotypes in acute respiratory distress syndrome: latent class analysis of data from two randomised controlled trials. Lancet Respir Med. 2014;2(8):611-20.

40. Calfee CS, et al. Acute respiratory distress syndrome subphenotypes and differential response to simvastatin: secondary analysis of a randomised controlled trial. Lancet Respir Med. 2018;6(9):691-8.

41. Johnson CL, Soeder Y, Dahlke MH. Concise review: Mesenchymal stromal cell-based approaches for the treatment of acute respiratory distress and sepsis syndromes. Stem Cells Transl Med. 2017;6(4):1141-51.

42. Albertine KH. Ultrastructural abnormalities in increased-permeability pulmonary edema. Clin Chest Med. 1985;6(3):345-69.

43. Bachofen M, Weibel ER. Structural alterations of lung parenchyma in the adult respiratory distress syndrome. Clin Chest Med. 1982;3(1):35-56.

44. Tomashefski JF Jr. Pulmonary pathology of the adult respiratory distress syndrome. Clin Chest Med. 1990;11(4):593-619.

45. Guerin C, et al. Open lung biopsy in nonresolving ARDS frequently identifies diffuse alveolar damage regardless of the severity stage and may have implications for patient management. Intensive Care Med. 2015;41(2):222-30.

46. Cardinal-Fernandez $P$, et al. The presence of diffuse alveolar damage on open lung biopsy is associated with mortality in patients with acute respiratory distress syndrome: a systematic review and metaanalysis. Chest. 2016;149(5):1155-64.

47. Holm BA, Notter RH, Finkelstein JN. Surface property changes from interactions of albumin with natural lung surfactant and extracted lung lipids. Chem Phys Lipids. 1985;38(3):287-98.

48. Holm BA, Notter RH. Effects of hemoglobin and cell membrane lipids on pulmonary surfactant activity. J Appl Physiol (1985). 1987;63(4):1434-42.

49. Wang Z, Notter RH. Additivity of protein and nonprotein inhibitors of lung surfactant activity. Am J Respir Crit Care Med. 1998;158(1):28-35.

50. dos Santos CC, et al. DNA microarray analysis of gene expression in alveolar epithelial cells in response to TNFalpha, LPS, and cyclic stretch. Physiol Genomics. 2004;19(3):331-42.

51. Torii K, et al. Higher concentrations of matrix metalloproteinases in bronchoalveolar lavage fluid of patients with adult respiratory distress syndrome. Am J Respir Crit Care Med. 1997;155(1):43-6.

52. Cross CE, Frei B, Louie S. The adult respiratory distress syndrome (ARDS) and oxidative stress: therapeutic implications. Adv Exp Med Biol. 1990;264:435-48.

53. Gonzalez PK, et al. Role of oxidant stress in the adult respiratory distress syndrome: evaluation of a novel antioxidant strategy in a porcine model of endotoxininduced acute lung injury. Shock. 1996;6(Suppl 1):S23-6.

54. Kumar KV, et al. Oxidant stress and essential fatty acids in patients with risk and established ARDS. Clin Chim Acta. 2000;298(1-2):111-20.

55. Lang JD, et al. Oxidant-antioxidant balance in acute lung injury. Chest. 2002;122(6 Suppl):314S-20S.

56. Metnitz PG, et al. Antioxidant status in patients with acute respiratory distress syndrome. Intensive Care Med. 1999;25(2):180-5.

57. Quinlan GJ, Evans TW, Gutteridge JM. Oxidative damage to plasma proteins in adult respiratory distress syndrome. Free Radic Res. 1994;20(5):289-98. 
58. Zhang H, Slutsky AS, Vincent JL. Oxygen free radicals in ARDS, septic shock and organ dysfunction. Intensive Care Med. 2000;26(4):474-6.

59. Amat M, et al. Evolution of leukotriene B4, peptide leukotrienes, and interleukin-8 plasma concentrations in patients at risk of acute respiratory distress syndrome and with acute respiratory distress syndrome: mortality prognostic study. Crit Care Med. 2000;28(1):57-62.

60. Antonelli M, et al. Leukotrienes and alpha tumor necrosis factor levels in the bronchoalveolar lavage fluid of patient at risk for the adult respiratory distress syndrome. Minerva Anestesiol. 1994;60(9):419-26.

61. Gadaleta D, Davis JM. Pulmonary failure and the production of leukotrienes. J Am Coll Surg. 1994;178(3):309-19.

62. Geuenich S, et al. Induction of leukotriene production by bleomycin and asparaginase in mast cells in vitro and in patients in vivo. Biochem Pharmacol. 1998;55(4):447-53.

63. Masclans JR, et al. Possible prognostic value of leukotriene $\mathrm{B}(4)$ in acute respiratory distress syndrome. Respir Care. 2007;52(12):1695-700.

64. Pritze S, Peskar BA, Simmet T. Release of eicosanoids and endothelin in an experimental model of adult respiratory distress syndrome. Agents Actions Suppl. 1992;37:41-6.

65. Devaney J, et al. Human mesenchymal stromal cells decrease the severity of acute lung injury induced by E. coli in the rat. Thorax. 2015;70(7):625-35.

66. Payne JE, et al. Activity of innate antimicrobial peptides and ivacaftor against clinical cystic fibrosis respiratory pathogens. Int $\mathrm{J}$ Antimicrob Agents. 2017;50(3):427-35.

67. Saiman L, et al. Cathelicidin peptides inhibit multiply antibiotic-resistant pathogens from patients with cystic fibrosis. Antimicrob Agents Chemother. 2001;45(10):2838-44.

68. Mokart D, et al. Deactivation of alveolar macrophages in septic neutropenic ARDS. Chest. 2003;124(2):644-52.

69. Yokoyama T, et al. Bacteremic and leukopenic pneumococcal pneumonia: successful treatment with antibiotics, pulse steroid, and continuous hemodiafiltration. J Infect Chemother. 2002;8(3):247-51.

70. Thommasen HV, et al. Transient leucopenia associated with adult respiratory distress syndrome. Lancet. 1984;1(8381):809-12.

71. Matthay MA, et al. Treatment with allogeneic mesenchymal stromal cells for moderate to severe acute respiratory distress syndrome (START study): a randomised phase 2 a safety trial. Lancet Respir Med. 2019;7(2):154-62.

72. Keto J, et al. Immunomonitoring of MSC-treated GvHD patients reveals only moderate potential for response prediction but indicates treatment safety. Mol Ther Methods Clin Dev. 2018;9:109-18.

73. Maziarz RT, et al. Single and multiple dose MultiStem (multipotent adult progenitor cell) therapy prophylaxis of acute graft-versus-host disease in myeloablative allogeneic hematopoietic cell transplan- tation: a phase 1 trial. Biol Blood Marrow Transplant. 2015;21(4):720-8.

74. Ardanaz N, et al. Inflammatory response to the administration of mesenchymal stem cells in an equine experimental model: effect of autologous, and single and repeat doses of pooled allogeneic cells in healthy joints. BMC Vet Res. 2016;12:65.

75. Assis AC, et al. Time-dependent migration of systemically delivered bone marrow mesenchymal stem cells to the infarcted heart. Cell Transplant. 2010;19(2):219-30.

76. Kraitchman DL, et al. Dynamic imaging of allogeneic mesenchymal stem cells trafficking to myocardial infarction. Circulation. 2005;112(10):1451-61.

77. Barbash IM, et al. Systemic delivery of bone marrowderived mesenchymal stem cells to the infarcted myocardium: feasibility, cell migration, and body distribution. Circulation. 2003;108(7):863-8.

78. Eggenhofer E, et al. Mesenchymal stem cells are short-lived and do not migrate beyond the lungs after intravenous infusion. Front Immunol. 2012;3:297.

79. Lohan P, et al. Third-party allogeneic Mesenchymal stromal cells prevent rejection in a pre-sensitized highrisk model of corneal transplantation. Front Immunol. 2018;9:2666.

80. Ko JH, et al. Mesenchymal stem/stromal cells precondition lung monocytes/macrophages to produce tolerance against Allo- and autoimmunity in the eye. Proc Natl Acad Sci U S A. 2016;113(1):158-63.

81. Peter Y, et al. CD45/CD11b positive subsets of adult lung anchorage-independent cells harness epithelial stem cells in culture. J Tissue Eng Regen Med. 2013;7(7):572-83.

82. Qiao PF, et al. Heat shock pretreatment improves stem cell repair following ischemia-reperfusion injury via autophagy. World J Gastroenterol. 2015;21(45):12822-34.

83. Kusuma GD, et al. Effect of the microenvironment on Mesenchymal stem cell paracrine Signaling: opportunities to engineer the therapeutic effect. Stem Cells Dev. 2017;26(9):617-31.

84. Najar M, et al. Insights into inflammatory priming of mesenchymal stromal cells: functional biological impacts. Inflamm Res. 2018;67(6):467-77.

85. Baer PC, et al. Effect of different preconditioning regimens on the expression profile of murine adipose-derived stromal/stem cells. Int $\mathrm{J}$ Mol Sci. 2018;19(6):E1719.

86. Walter J, Ware LB, Matthay MA. Mesenchymal stem cells: mechanisms of potential therapeutic benefit in ARDS and sepsis. Lancet Respir Med. 2014;2(12):1016-26.

87. Krasnodembskaya A, et al. Human mesenchymal stem cells reduce mortality and bacteremia in Gramnegative sepsis in mice in part by enhancing the phagocytic activity of blood monocytes. Am J Physiol Lung Cell Mol Physiol. 2012;302(10):L1003-13.

88. Hall SR, et al. Mesenchymal stromal cells improve survival during sepsis in the absence of heme oxygenase-1: the importance of neutrophils. Stem Cells. 2013;31(2):397-407. 
89. Krampera M, et al. Bone marrow mesenchymal stem cells inhibit the response of naive and memory antigen-specific $\mathrm{T}$ cells to their cognate peptide. Blood. 2003;101(9):3722-9.

90. Gupta $\mathrm{N}$, et al. Intrapulmonary delivery of bone marrow-derived mesenchymal stem cells improves survival and attenuates endotoxin-induced acute lung injury in mice. J Immunol. 2007;179(3):1855-63.

91. Curley GF, et al. Effects of intratracheal mesenchymal stromal cell therapy during recovery and resolution after ventilator-induced lung injury. Anesthesiology. 2013;118(4):924-32.

92. Lee JW, et al. Allogeneic human mesenchymal stem cells for treatment of $E$. coli endotoxininduced acute lung injury in the ex vivo perfused human lung. Proc Natl Acad Sci U S A. 2009;106(38):16357-62.

93. Lee JW, et al. Therapeutic effects of human mesenchymal stem cells in ex vivo human lungs injured with live bacteria. Am J Respir Crit Care Med. 2013;187(7):751-60.

94. McAuley DF, et al. Clinical grade allogeneic human mesenchymal stem cells restore alveolar fluid clearance in human lungs rejected for transplantation. Am J Physiol Lung Cell Mol Physiol. 2014;306(9):L809-15.

95. Park J, et al. Therapeutic effects of human mesenchymal stem cell microvesicles in an ex vivo perfused human lung injured with severe $E$. coli pneumonia. Thorax. 2019;74(1):43-50.

96. Patel SA, et al. Immunological properties of mesenchymal stem cells and clinical implications. Arch Immunol Ther Exp. 2008;56(1):1-8.

97. Nemeth K. Mesenchymal stem cell therapy for immune-modulation: the donor, the recipient, and the drugs in-between. Exp Dermatol. 2014;23(9):625-8.

98. Chan JL, et al. Antigen-presenting property of mesenchymal stem cells occurs during a narrow window at low levels of interferon- $\gamma$. Blood. 2006;107(12):4817-24.

99. Nauta AJ, et al. Donor-derived mesenchymal stem cells are immunogenic in an allogeneic host and stimulate donor graft rejection in a nonmyeloablative setting. Blood. 2006;108(6):2114-20.

100. Stagg J, et al. Interferon- $\gamma$-stimulated marrow stromal cells: a new type of nonhematopoietic antigenpresenting cell. Blood. 2006;107(6):2570-7.

101. Kim I, et al. Clinical implication of Allogenic implantation of Adipogenic differentiated adiposederived stem cells. Stem Cells Transl Med. 2014;3(11):1312-21.

102. Kurtzberg J, et al. Allogeneic human mesenchymal stem cell therapy (remestemcel-L, Prochymal) as a rescue agent for severe refractory acute graftversus-host disease in pediatric patients. Biol Blood Marrow Transplant. 2014;20(2):229-35.

103. Sbano P, et al. Use of donor bone marrow mesenchymal stem cells for treatment of skin allograft rejection in a preclinical rat model. Arch Dermatol Res. 2008;300(3):115-24.
104. Seifert M, et al. Detrimental effects of rat mesenchymal stromal cell pre-treatment in a model of acute kidney rejection. Front Immunol. 2012;3:202.

105. Curley GF, et al. Mesenchymal stem cells enhance recovery and repair following ventilator-induced lung injury in the rat. Thorax. 2012;67(6):496-501.

106. Gupta N, et al. Mesenchymal stem cells enhance survival and bacterial clearance in murine Escherichia coli pneumonia. Thorax. 2012;67(6):533-9.

107. Krasnodembskaya A, et al. Antibacterial effect of human mesenchymal stem cells is mediated in part from secretion of the antimicrobial peptide LL-37. Stem Cells. 2010;28(12):2229-38.

108. Krasnodembskaya A, et al. Human mesenchymal stem cells reduce mortality and bacteremia in gramnegative sepsis in mice in part by enhancing the phagocytic activity of blood monocytes. Am J Phys Lung Cell Mol Phys. 2012;302(10):L1003-13.

109. Xu J, et al. Mesenchymal stem cell-based angiopoietin-1 gene therapy for acute lung injury induced by lipopolysaccharide in mice. J Pathol. 2008;214(4):472-81.

110. Németh K, et al. Bone marrow stromal cells attenuate sepsis via prostaglandin E 2-dependent reprogramming of host macrophages to increase their interleukin-10 production. Nat Med. 2009;15(1):42.

111. Lee JW, et al. Concise review: mesenchymal stem cells for acute lung injury: role of paracrine soluble factors. Stem Cells. 2011;29(6):913-9.

112. Monsel A, et al. Therapeutic effects of human mesenchymal stem cell-derived microvesicles in severe pneumonia in mice. Am J Respir Crit Care Med. 2015;192(3):324-36.

113. Goolaerts A, et al. Conditioned media from mesenchymal stromal cells restore sodium transport and preserve epithelial permeability in an in vitro model of acute alveolar injury. Am J Phys Lung Cell Mol Phys. 2014;306(11):L975-85.

114. Phinney DG, et al. Mesenchymal stem cells use extracellular vesicles to outsource mitophagy and shuttle microRNAs. Nat Commun. 2015;6:8472.

115. Bruno S, et al. Mesenchymal stem cell-derived microvesicles protect against acute tubular injury. J Am Soc Nephrol. 2009;20(5):1053-67.

116. Zhu YG, et al. Human mesenchymal stem cell microvesicles for treatment of Escherichia coli endotoxin-induced acute lung injury in mice. Stem Cells. 2014;32(1):116-25.

117. Fang X, et al. Allogeneic human mesenchymal stem cells restore epithelial protein permeability in cultured human alveolar type II cells by secretion of angiopoietin-1. J Biol Chem. 2010;285(34):26211-22.

118. Islam $\mathrm{MN}$, et al. Mitochondrial transfer from bone-marrow-derived stromal cells to pulmonary alveoli protects against acute lung injury. Nat Med. 2012;18(5):759.

119. Ahmad T, et al. Miro1 regulates intercellular mitochondrial transport \& enhances mesenchymal stem cell rescue efficacy. EMBO J. 2014;33(9):994-1010. 
120. Li X, et al. Mitochondrial transfer of induced pluripotent stem cell-derived mesenchymal stem cells to airway epithelial cells attenuates cigarette smoke-induced damage. Am J Respir Cell Mol Biol. 2014;51(3):455-65.

121. Liu K, et al. Mesenchymal stem cells rescue injured endothelial cells in an in vitro ischemia-reperfusion model via tunneling nanotube like structuremediated mitochondrial transfer. Microvasc Res. 2014;92:10-8.

122. Rustom A, et al. Nanotubular highways for intercellular organelle transport. Science. 2004;303(5660):1007-10.

123. He K, et al. Long-distance intercellular connectivity between cardiomyocytes and cardiofibroblasts mediated by membrane nanotubes. Cardiovasc Res. 2011;92(1):39-47.

124. Önfelt B, et al. Structurally distinct membrane nanotubes between human macrophages support longdistance vesicular traffic or surfing of bacteria. J Immunol. 2006;177(12):8476-83.

125. Pasquier J, et al. Preferential transfer of mitochondria from endothelial to cancer cells through tunneling nanotubes modulates chemoresistance. J Trans1 Med. 2013;11(1):94.

126. Li X, et al. Mesenchymal stem cells alleviate oxidative stress-induced mitochondrial dysfunction in the airways. J Allergy Clin Immunol. 2018;141(5):163445. e5

127. Morrison TJ, et al. Mesenchymal stromal cells modulate macrophages in clinically relevant lung injury models by extracellular vesicle mitochondrial transfer. Am J Respir Crit Care Med. 2017;196(10):1275-86.

128. Jackson MV, et al. Mitochondrial transfer via tunneling nanotubes is an important mechanism by which mesenchymal stem cells enhance macrophage phagocytosis in the in vitro and in vivo models of ARDS. Stem Cells. 2016;34(8):2210-23.

129. Dorward DA, et al. Novel role for endogenous mitochondrial formylated peptide-driven formyl peptide receptor 1 signalling in acute respiratory distress syndrome. Thorax. 2017;72(10):928-36.

130. Bone NB, et al. Frontline science: D1 dopaminergic receptor signaling activates the AMPK-bioenergetic pathway in macrophages and alveolar epithelial cells and reduces endotoxin-induced ALI. J Leukoc Biol. 2017;101(2):357-65.

131. Jang $\mathrm{TH}$, et al. Cryopreservation and its clinical applications. Integr Med Res. 2017;6(1):12-8.

132. Haack-Sorensen M, Kastrup J. Cryopreservation and revival of mesenchymal stromal cells. Methods Mol Biol. 2011;698:161-74.

133. Quimby JM, et al. Safety and efficacy of intravenous infusion of allogeneic cryopreserved mesenchymal stem cells for treatment of chronic kidney disease in cats: results of three sequential pilot studies. Stem Cell Res Ther. 2013;4(2):48.
134. Galipeau J. The mesenchymal stromal cells dilemma--does a negative phase III trial of random donor mesenchymal stromal cells in steroid-resistant graft-versus-host disease represent a death knell or a bump in the road? Cytotherapy. 2013;15(1):2-8.

135. Francois M, et al. Cryopreserved mesenchymal stromal cells display impaired immunosuppressive properties as a result of heat-shock response and impaired interferon-gamma licensing. Cytotherapy. 2012;14(2):147-52.

136. Bianco P, et al. The meaning, the sense and the significance: translating the science of mesenchymal stem cells into medicine. Nat Med. 2013;19(1):35-42.

137. Bianco P, et al. Regulation of stem cell therapies under attack in Europe: for whom the bell tolls. EMBO J. 2013;32(11):1489-95.

138. Wagner B, Henschler R. Fate of intravenously injected mesenchymal stem cells and significance for clinical application. Adv Biochem Eng Biotechnol. 2013;130:19-37.

139. Ankrum J, Karp JM. Mesenchymal stem cell therapy: two steps forward, one step back. Trends Mol Med. 2010;16(5):203-9.

140. Moll G, et al. Do cryopreserved mesenchymal stromal cells display impaired immunomodulatory and therapeutic properties? Stem Cells. 2014;32(9):2430-42.

141. Copland IB, Galipeau J. Death and inflammation following somatic cell transplantation. Semin Immunopathol. 2011;33(6):535-50.

142. Ricklin D, et al. Complement: a key system for immune surveillance and homeostasis. Nat Immunol. 2010;11(9):785-97.

143. Kemper C, Atkinson JP, Hourcade DE. Properdin: emerging roles of a pattern-recognition molecule. Annu Rev Immunol. 2010;28:131-55.

144. Roos A, et al. Mini-review: a pivotal role for innate immunity in the clearance of apoptotic cells. Eur $\mathrm{J}$ Immunol. 2004;34(4):921-9.

145. Li Y, Lin F. Mesenchymal stem cells are injured by complement after their contact with serum. Blood. 2012;120(17):3436-43.

146. Murray PJ. Macrophage polarization. Annu Rev Physiol. 2017;79:541-66.

147. Sica A, Mantovani A. Macrophage plasticity and polarization: in vivo veritas. J Clin Invest. 2012;122(3):787-95.

148. Van Dyken SJ, Locksley RM. Interleukin-4- and interleukin-13-mediated alternatively activated macrophages: roles in homeostasis and disease. Annu Rev Immunol. 2013;31:317-43.

149. Baksh D, Song L, Tuan R. Adult mesenchymal stem cells: characterization, differentiation, and application in cell and gene therapy. J Cell Mol Med. 2004;8(3):301-16.

150. Baksh D, Yao R, Tuan RS. Comparison of proliferative and multilineage differentiation potential of human mesenchymal stem cells derived from 
umbilical cord and bone marrow. Stem Cells. 2007;25(6):1384-92.

151. Wu L-F, et al. Differentiation of Wharton's jelly primitive stromal cells into insulin-producing cells in comparison with bone marrow mesenchymal stem cells. Tissue Eng Part A. 2009;15(10):2865-73.

152. Chen M-Y, et al. Endothelial differentiation of Wharton's jelly-derived mesenchymal stem cells in comparison with bone marrow-derived mesenchymal stem cells. Exp Hematol. 2009;37(5):629-40.

153. Peng L, et al. Comparative analysis of mesenchymal stem cells from bone marrow, cartilage, and adipose tissue. Stem Cells Dev. 2008;17(4):761-74.

154. Kern $S$, et al. Comparative analysis of mesenchymal stem cells from bone marrow, umbilical cord blood, or adipose tissue. Stem Cells. 2006;24(5):1294-301.

155. Jung $\mathrm{H}-\mathrm{G}$, et al. Effects of harvesting sites and ages on adipose tissue-derived stem cells in rat. Tissue Eng Regen Med. 2014;11(2):137-42.

156. Mueller SM, Glowacki J. Age-related decline in the osteogenic potential of human bone marrow cells cultured in three-dimensional collagen sponges. J Cell Biochem. 2001;82(4):583-90.

157. Cianfarani F, et al. Diabetes impairs adipose tissue-derived stem cell function and efficiency in promoting wound healing. Wound Repair Regen. 2013;21(4):545-53.

158. Sun Y, et al. Mesenchymal stem cells from patients with rheumatoid arthritis display impaired function in inhibiting Th17 cells. J Immunol Res. 2015;2015:284215.

159. Antebi B, et al. The effect of acute respiratory distress syndrome on bone marrow-derived mesenchymal stem cells. Stem Cell Res Ther. 2018;9(1):251.

160. Yang H, et al. Therapeutic effect of TSG-6 engineered iPSC-derived MSCs on experimental periodontitis in rats: a pilot study. PLoS One. 2014;9(6):e100285.

161. Fu Q, et al. Mesenchymal stem cells derived from human induced pluripotent stem cells modulate T-cell phenotypes in allergic rhinitis. Allergy. 2012;67(10):1215-22.

162. Cheng P-P, et al. iPSC-MSCs combined with low-dose rapamycin induced islet allograft tolerance through suppressing Th1 and enhancing regulatory T-cell differentiation. Stem Cells Dev. 2015;24(15):1793-804.

163. Zhang Y, et al. Improved cell survival and paracrine capacity of human embryonic stem cell-derived mesenchymal stem cells promote therapeutic potential for pulmonary arterial hypertension. Cell Transplant. 2012;21(10):2225-39.

164. Sun YQ, et al. Human pluripotent stem cellderived mesenchymal stem cells prevent allergic airway inflammation in mice. Stem Cells. 2012;30(12):2692-9.

165. Sun YQ, et al. Insensitivity of human iPS cells-derived mesenchymal stem cells to interferon- $\gamma$-induced
HLA expression potentiates repair efficiency of hind limb ischemia in immune humanized NOD Scid gamma mice. Stem Cells. 2015;33(12):3452-67.

166. Frobel J, et al. Epigenetic rejuvenation of mesenchymal stromal cells derived from induced pluripotent stem cells. Stem Cell Reports. 2014;3(3):414-22.

167. Sheaffer KL, et al. DNA methylation is required for the control of stem cell differentiation in the small intestine. Genes Dev. 2014;28(6):652-64.

168. Ronen D, Benvenisty N. Genomic stability in reprogramming. Curr Opin Genet Dev. 2012;22(5):444-9.

169. Laffey JG, Matthay MA. Fifty yeawrs of research in ARDS. Cell-based therapy for acute respiratory distress syndrome. Biology and potential therapeutic value. Am J Respir Crit Care Med. 2017;196(3):266-73.

170. Zheng G, et al. Treatment of acute respiratory distress syndrome with allogeneic adipose-derived mesenchymal stem cells: a randomized, placebocontrolled pilot study. Respir Res. 2014;15:39.

171. Wilson JG, et al. Mesenchymal stem (stromal) cells for treatment of ARDS: a phase 1 clinical trial. Lancet Respir Med. 2015;3(1):24-32.

172. Kaplan A, et al. Impact of starting material (fresh versus cryopreserved marrow) on mesenchymal stem cell culture. Transfusion. 2017;57(9):2216-9.

173. Islam D, et al. Identification and modulation of microenvironment is crucial for effective MSC therapy in acute lung injury. Am J Respir Crit Care Med. 2019;199(10):1214-24.

174. Gattinoni L, et al. Acute respiratory distress syndrome caused by pulmonary and extrapulmonary disease. Different syndromes? Am J Respir Crit Care Med. 1998;158(1):3-11.

175. Hoelz C, et al. Morphometric differences in pulmonary lesions in primary and secondary ARDS. A preliminary study in autopsies. Pathol Res Pract. 2001;197(8):521-30.

176. Negri EM, et al. Acute remodeling of parenchyma in pulmonary and extrapulmonary ARDS. An autopsy study of collagen-elastic system fibers. Pathol Res Pract. 2002;198(5):355-61.

177. Pelosi $\mathrm{P}$, et al. Pulmonary and extrapulmonary acute respiratory distress syndrome are different. Eur Respir J Suppl. 2003;42:48s-56s.

178. Mrozek S, et al. Elevated plasma levels of sRAGE are associated with nonfocal CT-based lung imaging in patients with ARDS: a prospective Multicenter study. Chest. 2016;150(5):998-1007.

179. Rezoagli E, Magliocca A, Catenacci SS. Identification of biological phenotypes in acute respiratory distress syndrome. From biomarkers to clinical outcome. Am J Respir Crit Care Med. 2018;197(9):1209-11.

180. Kim SJ, et al. Recovery from lung injury in survivors of acute respiratory distress syndrome: difference between pulmonary and extrapulmonary subtypes. Intensive Care Med. 2004;30(10):1960-3. 
181. Ketoconazole for early treatment of acute lung injury and acute respiratory distress syndrome: a randomized controlled trial. The ARDS Network. JAMA. 2000;283(15):1995-2002.

182. Randomized, placebo-controlled trial of lisofylline for early treatment of acute lung injury and acute respiratory distress syndrome. Crit Care Med. 2002;30(1):1-6.

183. Brower RG, et al. Higher versus lower positive end-expiratory pressures in patients with the acute respiratory distress syndrome. $\mathrm{N}$ Engl $\mathrm{J}$ Med. 2004;351(4):327-36.
184. Galleu A, et al. Apoptosis in mesenchymal stromal cells induces in vivo recipient-mediated immunomodulation. Sci Transl Med. 2017;9(416):eaam7828.

185. Sherman SE, et al. High aldehyde dehydrogenase activity identifies a subset of human Mesenchymal stromal cells with vascular regenerative potential. Stem Cells. 2017;35(6):1542-53.

186. Chinnadurai R, et al. Potency analysis of Mesenchymal stromal cells using a combinatorial assay matrix approach. Cell Rep. 2018;22(9):2504-17. 